\title{
Francisco Zúñiga Díaz o la imagen en los talleres de literatura
}

Hiram Castro Carvajal

Colegio Seminario

San José, Costa Rica

Al maestro, al amigo, al Escritor... porque Chico, la verdad sea dicha, nunca te fuiste. Aún estás aquí, con nosotros. Gracias.

\section{Resumen}

A partir de la imagen lezamiana- de José Lezama Lima (Cuba)-, el autor aborda la obra poética del escritor costarricense Francisco Zúñiga Díaz, quien promovió la creación poética entre los jóvenes por medio de sus talleres literarios en San José, Costa Rica.

Palabras clave: Francisco Zúñiga Díaz, literatura costarricense, talleres literarios, soneto

\begin{abstract}
From the idea of "Lezamian image"- José Lezama Lima (Cuba)-, the author analyzes the poetic work of Francisco Zúñiga Díaz, a Costa Rican contemporary writer who promoted poetic creation among young people through his literary ateliers in San José, Costa Rica.
\end{abstract}

Keywords: Franciso Zúñiga Díaz, Costa Rican literature, literary ateliers, sonet 


\section{La imagen lezamiana o la búsqueda de la metáfora}

A través de múltiples ensayos, muchos de ellos recogidos en Ensayos en la Habana, el poeta cubano José Lezama Lima se refiere al concepto tradicional de metáfora con el sugestivo y sugerente nombre de "Imagen". En dicho volumen, Lezama no relaciona el concepto poético tan directamente con los griegos, quienes explotaron al máximo sus posibilidades entre las culturas antiguas, sino con los textos del egipcio Libro de los muertos. Además, vincula la presencia de la metáfora, o imagen, en la poesía griega, no como un rasgo distintivo de los líricos o épicos helénicos, sino como un acto de responsabilidad absoluta de sus iniciáticos, a través de los ritos órficos. No puede olvidarse que Apolo estaba relacionado tanto con la lira y las musas como con los oráculos, especialmente el de Delfos, y su particular mito de la serpiente.

Lezama explica que la famosa comparación de un objeto, mediante el nombramiento de otro, no es comparable sino con el acto religioso de ocultar el origen del mito. Recordemos que la manifestación de lo divino en la práctica religiosa recibe el nombre de "misterio". Dicho mecanismo lo explica a cabalidad en "La sierpe de don Luis de Góngora", uno de los ensayos capitales y más profundos en el referido volumen. El análisis de las metáforas del poema culterano, tanto en la Fábula de Polifemo y Galatea, como en su Soledad primera ponen de manifiesto el uso de la metáfora como recurso para nombrar un concepto que debe ser encontrado por el lector, como si la idea fuese un objeto sagrado, y comprender su relación con él a partir de la palabra, una epifanía.

Pero Lezama se solazaba no en el mecanismo de ocultamiento, cansino y repetitivo en la mayoría de poetas culteranos - imitadores, más que seguidores, de Góngora - sino en el uso imaginativo de las palabras usadas para ocultar el concepto. Es decir, Lezama hallaba belleza y placer no en las palabras usadas para ocultar, sino en la imaginación que se requería para relacionar el concepto por transmitir con las palabras empleadas. Para Lezama, la magia estaba no en describir el "caracol" como una "joroba de marfil", sino en los múltiples significados que tendría, para los lectores diversos de un poema, la expresión "joroba de marfil".

De sobra conocido resulta el ejemplo del árbol en Saussure. Si colocamos la palabra "árbol" en un pizarrón, cada alumno se imaginará un árbol diferente, según su propio bagaje y experiencia. Serán muy diferentes, pero al final, seguirán siendo árboles. Para Lezama, la imagen tiene la riqueza del ejercicio del árbol, pero múltiples lectores imaginarían cosas que, talvez, no se relacionen con un árbol. La idea de la interpretación personal en la literatura estaría muy presente, según la noción de imagen de Lezama, tan distante de la arquetípica metáfora del rigor académico. Pero bueno, por alguna buena razón, los poetas escriben y los académicos analizan, aunque a veces hay quienes cruzan tales linderos.

Por eso, resulta sumamente interesante que hablemos de cursos de literatura. Deberíamos hablar de cursos sobre la historia e interpretación de la literatura, pues los 
cursos de literatura deberían enseñarnos a escribir, a hacer y producir literatura, cosa que no sucede con frecuencia en los salones de clase. Para que eso fuese posible, los autores, poetas, narradores, dramaturgos y ensayistas deberían ser quienes impartan dichos cursos. Horror vacui: Hay escritores que sí dan clases, pero lo hacen con un sentido totalmente académico.

Es aquí donde aparecen los llamados talleres de literatura, llamados así en referencia a las asociaciones gremiales de la Edad Media. Hay quienes ven, incluso, su misma estructura y distribución de poder: el maestro, los hermanos y los aprendices. Otros, menos fastuosos y conspicuos, solo se atreven a dar breves seminarios y capacitaciones sobre algunos recursos estilísticos puntuales.

Sin embargo, la mecánica de los talleres en Costa Rica ha experimentado un auge en los últimos treinta años. Hasta resulta gracioso descubrir grupos que utilizan otra designación, porque la de taller de literatura les resulta vergonzosa y denigrante. Esto se debe a la noción de taller como trabajo y reparación de manufactura.

Lo que sí llama poderosamente la atención sobre los talleres literarios en Costa Rica, es su fidelidad a un modelo metafórico o de imagen. Los talleres nacionales se definen, básicamente, a partir de la visión estética que se tenga sobre el quehacer poético, sobre la construcción del texto poético, y sobre el uso de su recurso más importante: la metáfora. Normalmente, la figura del maestro o mentor pasa a segundo plano, y se la evoca, casi siempre, solo porque resulta conocida la postura ideológica y creativa de dicho agente creador.
Uno de los grupos más importantes de nuestra producción poética se definió a partir de la creación de poesía trascendental, y elaboró todo un manifiesto para justificar su opinión sobre lo que la poesía y la metáfora debían ser. Nos referimos, claramente, al llamado Grupo de poetas trascendentalistas. A este grupo es al que le debemos la estructuración de la primera gran noción colectiva de literatura desde la Generación del Olimpo.

Dicho esfuerzo quedó reunido en el volumen titulado Manifiesto trascendentalista. Como todo manifiesto de vanguardia, evocando al surrealismo, a Tzara y Dadá, el Manifiesto es un texto poco congruente, $\mathrm{y}$ bastante contradictorio en algunos segmentos. Pero, a la vez, significa un esfuerzo de honestidad intelectual por encontrar un rumbo para el quehacer poético, o lo que se considera que debería ser ese quehacer en el país.

Durante años, los poetas costarricenses, jóvenes y consolidados han declarado seguir o apartarse, total o parcialmente, de las posturas del Manifiesto. Pero, sin lugar a dudas, cumplió con su objetivo de ser un norte, o al menos, un punto de partida. Sin embargo, no deja de resultar curioso que, desde que apareció el Manifiesto, la gran mayoría de talleres literarios del país se definan a partir del concepto particular de metáfora que cada agrupación utilice. Todos los grupos literarios nacionales, llámense o no talleres, se identifican a partir del uso de tal o cual noción de metáfora. Las variantes abundan en cuanto a tema, vocabulario, uso social, etc.

Los poetas que han publicado en Costa Rica, desde la aparición del Manifiesto, siempre se 
refieren al uso particular de sus metáforas, su contenido, su mensaje social o la ausencia de él. Esto puede entenderse debido a la influencia dominante y absoluta de la lectura nerudiana entre nuestros poetas.

La veneración de la palabra metáfora, en nuestra poesía, no puede explicarse si no es a través de la sublimación de la poesía de Pablo Neruda en sus trabajos. La metáfora nerudiana recorre nuestra poesía, reforzada por la difusión y el empuje dado por el maestro Isaac Felipe Azofeifa. El mismo Manifiesto Trascendentalista respira los inciensos eclesiásticos de la metáfora nerudiana en sus páginas.
Interesante juicio ofrece, al respecto, Adolfo Herrera García, a propósito del primer libro de Zúñiga, Trillos y nubes (1965): "Revela un espíritu tan delicado como un poeta de verdad, llegando a veces hasta conquistarle la calidad poemática a varios de sus cuentos."

Resulta refrescante encontrar en un autor costarricense el gusto por la imagen lezamiana. Sorprendente, además, resulta descubrir que dicho autor, además de poeta, es un narrador. $\mathrm{Y}$ lo realmente fascinante en todo esto: dicho escritor dirige un taller de literatura, y en el lugar menos pensado.

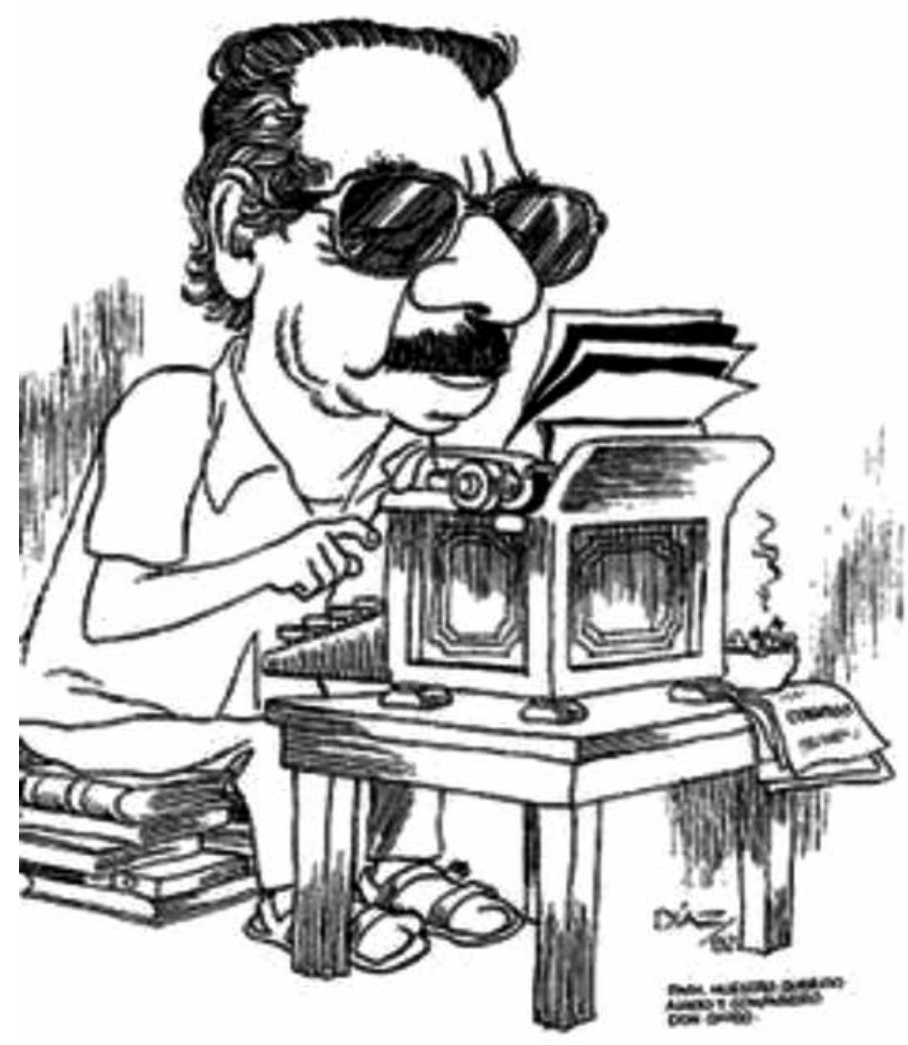

Francisco Zúñiga. Caricatura de Hugo Díaz. 


\section{¿Quién fue Chico Zúñiga?}

"Desde ahora en adelante seguirá siendo usted mi maestro preferido." José Alberto Arenas

El escritor Francisco Zúñiga Díaz nació en la ciudad de Esparza, provincia de Puntarenas, el 12 de julio de 1931.

Sus carreras literaria y profesional van de la mano al viajar a San José. Tras su contratación en el Instituto Nacional de Seguros en 1955, es uno de los fundadores de la Unión de Personal de dicha institución, UPINS. Tres años más tarde, con la conveniencia de horarios, ingresa en la Universidad de Costa Rica (UCR), donde se graduará como contador. Estos años de consolidación laboral y académica le abren las puertas para un futuro más provechoso. Publica su primer libro, el volumen de cuentos Trillos y nubes, en 1965.

El año 1965 resulta uno de los más fructíferos. En primera instancia, es designado vicepresidente de UPINS, a la par de Vocal y Comisionado Responsable del Círculo de Poetas Costarricenses. Y, mientras Isaac Felipe Azofeifa contribuye con el enriquecimiento cultural del país trayendo libros de la vanguardia sudamericana a nuestro país, Zúñiga Díaz establece un convenio con el Instituto Chileno de Literatura, para enviar libros costarricenses al país andino. Tal iniciativa conlleva, como un beneficio personal posterior, publicar su segundo libro de cuentos, La mala cosecha, en Santiago de Chile, dos años más tarde.

Al año siguiente, el 23 de febrero de 1968, se casa en la catedral de San José con Elsa María Juana Francisca Sáenz Ferreto, hija de Carlos Luis Sáenz y Adela Ferreto. Asimismo, participa como delegado en varias actividades internacionales en Rio de Janeiro, por su calidad como empleado bancario y de seguros, incluyendo un Seminario para Líderes Sindicales, a la vez que asume la presidencia de UPINS. Junto a otros compañeros, funda la Federación de Empleados Bancarios y de Seguros, FEBAS. A su vez, ingresa a la Asociación de Autores y Compositores de obras literarias, artísticas y científicas de Costa Rica. En 1970, es nombrado fiscal en esta Asociación.

Uno de los años más completos y satisfactorios, tanto en el plano personal como el artístico, será 1971. En primera instancia, Zúñiga se convierte en director de la Editorial Costa Rica (ECR), puesto que ocupó durante doce años, hasta 1983. Además, el año concluye de gran forma para él, pues el 6 de noviembre nace su único hijo, Carlos Francisco Zúñiga Sáenz.

Cualquier otro, al ocupar el cargo de Director de la editorial del Estado, se hubiera permitido instalarse definitivamente como una figura en el corpus tradicional de nuestra literatura, además de facilitar la publicación de sus propias obras; sin embargo, tratándose de Zúñiga, esto no podía pasar, y nunca sucedió. Más bien, utilizó esta posición de privilegio para allanarle el camino a una serie de escritores jóvenes. Tal era una muestra de su honradez y generosidad de carácter.

En años subsiguientes, participa como jurado en varios premios literarios para el INS y la UCR.

Encontramos en 1976 otro de sus años definitivos. Publica uno de sus libros de 
cuentos más importante, Los dos minutos y otros cuentos, a la vez que funda la obra de su vida y razón de este ensayo: el Café Cultural del INS. Ubicada al costado este de la institución, la casona del café albergó salas de artes marciales, pintura, escritura, baile y teatro. Desde ahí, Zúñiga dirigió uno de los talleres literarios más prestigiosos y celebrados de nuestro país, la publicación de libros de sus miembros y colaboradores, así como compartir la responsabilidad en el nacimiento de proyectos literarios semejantes, como en Pérez Zeledón, Turrialba y, principalmente, San Ramón.

En los años siguientes fue jurado, tanto en las ramas Joven Creación y Carmen Lyra de la ECR, como para Premios Nacionales y de la UCR, y publicó varias obras de poesía y cuento. Entre sus publicaciones, destacan Sonetos de amor en bicicleta (1977), El viento viejo (1978), su antología El soneto en la poesía costarricense (1979) y Geografía sencilla (1980).

De manera especial, resalta su labor como editor, ayudando a muchos escritores noveles a abrirse campo en las letras nacionales, colaboración que brindó tanto dentro como fuera de la ECR. Un detalle sorprendente en la publicación de la antología sobre el soneto costarricense es que Zúñiga la dejó incompleta adrede, hace falta un autor en ella. Zúñiga Díaz era un sonetista de primera línea, y tuvo todo el poder para incluirse a sí mismo en dicha antología, pero no lo hizo. En lugar de eso, prefirió que sonetistas como Aguilar y Picado tuvieran las páginas y el reconocimiento que él sentía que la comunidad académica había pasado por alto. Ecce homo.
Posteriormente, su actividad en el mundo cultural sucede entre actividades que organiza y reconocimientos a su labor. También sus luchas en el ámbito sindical, junto a sus compañeros del INS, lo convierten en un estandarte institucional. Esta bonanza laboral y literaria se confabula para la publicación de su volumen de cuentos más reconocido por la prensa cultural costarricense: Yo no tengo ningún muerto (1986).

La primera mitad de la década de los noventa fue particularmente fructífera para Zúñiga Díaz, pues estuvo llena de logros personales y colectivos. Publica dos de sus obras más recordadas: la voluminosa y valiosísima investigación Carlos Luis Sáenz: el escritor, el educador y el revolucionario (1991), mientras la EUNED le publica su último volumen de cuentos, $L a$ encerrona de la Chupeta y otros desbarajustes (1996), uno de sus trabajos más logrados, y le da el mérito y homenaje de publicarlo como el número 27 de su colección Vieja y nueva narrativa costarricense.

Una de sus mayores realizaciones personales vino en 1995, cuando el poeta, cuentista e investigador pudo concretar el sueño de toda una vida literaria: publicar una novela. Su trabajo ...Y hubo un pueblo de niños (1995) fue uno de los proyectos en los que más trabajó en sus últimos años, y presintiendo la muerte, no quiso que sus fuerzas se rindieran sin antes haberlo publicado. Fue uno de los momentos más emocionantes de su vida, y a pesar de los terribles quebrantos en su salud, el brillo de sus ojos resultó más que elocuente.

En cuanto a sus actividades con el Café Cultural, organizó recitales de poesía y 
visitas a San Ramón, Pérez Zeledón y Turrialba. Organizó un recital-homenaje en el INS por el fallecimiento de su amigo, el poeta Alfredo Cardona Peña y el I Encuentro de Escritores en San Ramón, donde se contó con la presencia, entre otros autores, de los novelistas José León Sánchez y Fernando Contreras Castro.

Sin embargo, lo que más le llenaría de orgullo sería la creación de nuevos talleres literarios. En 1991, y con la colaboración del poeta y académico Carlos Villalobos, surge el Taller Literario Rafael Estrada, en San Ramón, bautizado así en honor al gran poeta ramonense. Al año siguiente, funda su obra más generosa y humana, el Taller Literario de la Asociación Gerontológica Costarricense (AGECO). Ambos talleres continúan vigentes a la fecha. En el caso del taller de San Ramón, la faena es continuada por Carlos Villalobos y toda una generación de valiosos poetas ramonenses. En el caso del Taller de AGECO, su exalumno y amigo, el poeta Henry López, continúa tan noble y humanitaria tarea.

La década de los noventa también estuvo marcada, en su caso, por los quebrantos de salud generados por el consumo de tabaco. Su enfisema y la programación de quimioterapia en el Hospital México estuvieron a cargo de un doctor, quien fumaba mientras lo atendía en su consultorio. Zúñiga siempre hizo mofa del episodio, intentando restarle importancia a su padecimiento.

Pero el cáncer no perdona a nadie, aunque se burle de las ironías médicas. El enfisema pulmonar terminó imponiéndose. Suspende la quimioterapia y se refugia en su casa de Barrio México, bajo el cuidado de sus hermanas. Allí, recibe la visita de sus amigos, ya muy débil y con un tanque de oxígeno a su lado. Hasta el último de sus días, recibe a todos con una sonrisa. Francisco Zúñiga Díaz fallece el 28 de abril de 1997, en su casa de habitación, en su muy querido Barrio México.

$\mathrm{Su}$ biblioteca personal, una de las más completas que se haya visto en una casa particular en nuestro país, terminó como él hubiese querido: repartida entre todos sus amigos y discípulos. Aún después de su muerte, continuó transmitiendo sus conocimientos literarios a los más jóvenes, por medio de sus libros. Algunos de ellos, por la extrañeza de sus títulos, o lo invaluable de sus dedicatorias, ni siquiera encuentran ejemplares semejantes en la propia Biblioteca Nacional.

Un par de meses después de su fallecimiento, el Café Cultural del INS publica una antología de los miembros del Café, Luna entre milpas (1997), como un reconocimiento colectivo e institucional a su labor. Su recuerdo permanece intacto entre aquellos a quienes ayudó a publicar, quienes estuvieron bajo su tutela en un taller literario o, simplemente, compartieron con él en su ambiente laboral.

Prácticamente no hay un lugar de Costa Rica donde no se le recuerde con cariño. Muestra patente de eso se vivió en San Isidro de El General, cuando se efectuó el II Encuentro de Escritores, entre el 15 y el 18 de noviembre de 2012. El encuentro llevó por nombre Francisco Zúniga, in memoriam, recuerdo y homenaje más que merecidos para uno de los autores más lúcidos, e injustamente olvidados, que ha producido este país. 
Afortunadamente, su calidad literaria, su humildad, sencillez y don de gentes, hacen imposible que quienes lo conocimos podamos olvidarlo. Eso es lo que nos ha permitido rescatarlo del olvido y recuperarlo, no tanto para nosotros, sino para las futuras generaciones.

\section{El cuentista}

"Francisco Zúñiga Díaz escribe como al lector costarricense le gusta que le escriban." Alberto Cañas

Francisco Zúñiga Díaz editó y publicó siete volúmenes de cuentos, además de publicar un cuento largo, "Aquí voy yo, Andrés", en el Anuario del cuento costarricense (1968), una publicación especial que la Editorial Costa Rica realizó al año siguiente. Años más tarde, el cuento sería publicado nuevamente, como parte de su libro Los dos minutos y otros cuentos (1976),

Durante sus charlas en la cotidianeidad del taller, Zúñiga defendió principios teóricos básicos y universalmente aceptados, como la brevedad natural del cuento debido a sus pocos personajes y el tema central por narrar, la estructura tripartita de introducción, nudo y desenlace. Sin embargo, le gustaba sazonar algunos de esos conceptos.

Quizá lo más irreverente de sus comentarios venía con el desenlace. Para Zúñiga, el final del cuento debe ser impredecible, sorprendente, arrollador. Un cuento fracasa si el lector ya sabe cómo termina. Zúñiga defiende la sorpresa como el alma del cuento, su esencia, su recurso más preciado.

Un ejemplo de esto lo encontramos en su primer tomo de cuentos, Trillos y nubes
(1965). El cuento La luz de muerto nos retrata, de cuerpo entero, su gusto por el final inesperado y sorpresivo:

Y ya entre risas, contaron lo de la luz de muerto.

Allí Carmona, hecho también un mar de risa, besó como desesperado a la botella hasta dejarla seca.

-No jodan. Hace tres noches que persigo a un zorro que me jode el gallinero y ustedes con sus pendejeras. ¿No puede un renco salir con carbura de noche?

La edición de la obra está muy bien cuidada y contó con dibujos del artista nacional Juan Manuel Sánchez, tanto para la portada como para cada uno de los cuentos del volumen, el cual fue bien acogido y recibió elogiosos comentarios de parte de Mario Picado, Alfredo Vincenzi y Samuel Rovinski, entre otros.

$\mathrm{Su}$ segundo volumen de cuentos fue $L a$ mala cosecha (1967), publicado en Chile. Zúñiga, al igual que Isaac Felipe Azofeifa y Joaquín Gutiérrez, estrecharon profundos lazos literarios y de amistad con autores chilenos. Fruto de esos intercambios fue el envío de libros costarricenses a Chile, mientras en el país entraron textos de los principales autores de vanguardia del cono sur, incluyendo al maestro de Isla Negra. Además, textos de Azofeifa, Gutiérrez y Zúñiga fueron publicados en Santiago de Chile, como este volumen.

En un texto breve y delicioso, "La Fiesta", el último del volumen publicado en tierras 
andinas, se nos cuenta el abandono que sufre Leoncio por parte de su mujer. El ahora padre soltero debe hacerle frente a una marimba de cinco chiquillos. Finalmente, su mujer, abandonada por su amante Beltrán, con el rabo entre las piernas, regresa a su lado. Cada evento es "festejado" por el protagonista en la cantina del pueblo. De nuevo, el final sorpresivo no nos permite reponernos:

Y en el mostrador de la cantina:

Y que querías que yo hiciera, Manuel: vieras qué contentera la de los carajillos. ¡Parece que están de fiesta!

“Aquí voy yo, Andrés" (1968) es un cuento publicado, como se dijo, en una antología de cuentos que se suponía de carácter anual, que publicaría la Editoriall de Costa Rica. Alberto Cañas era uno de los encargados de dirigir la colección. Se trata de un cuento muy urbano y moderno, de cómo un joven seducido por la velocidad de su auto, produce una muerte en carretera tras un aparatoso accidente. Un texto muy interesante que deberían leer nuestras nuevas generaciones, en el marco de la lucha contra la mortalidad vial.

En este cuento ya no apreciamos el final sorpresivo, sino que se nos presenta la imagen lezamiana en todo su esplendor. La angustia, la imposibilidad del hecho, el trágico fin de sus esperanzas; toda esa vorágine de pensamientos y emociones está presente en las líneas finales de Zúñiga. El autor utiliza la imagen poética en este cuadro descriptivo para ocultar, y desatar al mismo tiempo, las múltiples sensaciones que devoran a Andrés y lo destruyen. El joven Andrés, quien irresponsablemente ha segado una vida con su volante y su acelerador:

Ya el transeúnte yacía sin vida sobre el pavimento húmedo. Uno que otro reflejo azul, rojo, amarillo, azul, de los resplandores neón, se le anidaba en las facciones repletas de muerte. Las manos de Andrés, llenas de sangre, todavía se crispaban, en ademán de círculo, como si aún apretaran el cuello del hombre. Todavía se cerraban, en remedo de puños, como si aún golpearan al contrincante. Todavía estilaban en chorrear de angustia, intensificando el rojo de los reflejos.

Sobre este cuento, ya nos dirá el propio Alberto Cañas:

...ha trazado el recién debutante Zúñiga Díaz el mejor cuento que hatsa la fecha le conocemos. Finamente observado con una temática moderna, trae a su autor hacia las formas urbanas que venía bordeando y lo lanza a la ciudad con buenos auspicios.

Los criterios de don Alberto no pueden ser más precisos ni valiosos. Ciertamente, en Trillos y nubes y La mala cosecha, Zúñiga desgarra a sus personajes y los exhibe en un cuadro humano en la periferia de la ciudad, cuando no en la zona rural, a la cual se siente tan cercano el autor nacido en Esparza. "Aquí voy yo, Andrés", rompe con el espacio tradicional de la narrativa de Zúñiga y se convierte en su primer 
esfuerzo por dominar la región de las sombras artificiales: la ciudad.

La transición del espacio se consolida cuando la ECR publica el volumen Los dos minutos y otros cuentos (1976). El humor que se le ha escapado a Zúñiga en los volúmenes anteriores vuelve una vez más, pero esta vez transfigurado en figura poética.

La ironía irrumpe en este volumen como su marca personal de escritor, esa ironía que se proyecta en la célebre imagen de la amarga victoria, la misma que inunda las comisuras de la sonrisa del héroe vencido y del antihéroe. Esa sonrisa que le conocemos a Zúñiga por su credo literario: Hemingway, Steinbeck y Faulkner, Fallas y Herrera García.

Y el anuncio se proclama a los cuatro vientos en el cuento principal del volumen, "Los dos minutos:"

Es duro. Tremendamente duro. Imagínese usted: "Tienes dos minutos para que digas en dónde están los otros. Si no abres el pico fusilaremos a tu padre"

Recuerde usted, eso sí, una cosa: él me suplicó con una sonrisa que no dijera nada.

El poeta Mario Picado emite el siguiente criterio sobre el libro:

Un estilo nuevo y diferente de Zúñiga Díaz que nos muestra su versatilidad y dominio de la narrativa en sus variados matices, acordes a las corrientes contemporáneas, y que hacen este libro agradable, directo...
Pero Zúñiga no está listo para abandonar su querida zona rural, su querido puerto del Pacífico. Es por eso que vuelve a sorprender, dos años después de la renovación técnica que le supuso Los dos minutos. Y lo hace con uno de sus mejores libros de cuentos: El viento viejo (1978).

El cuento de espacio rural, al mejor estilo de Carlos Salazar Herrera, es un elemento en el que Zúñiga, como cuentista, se siente a sus anchas. Gran ejemplo lo constituye el cuento "El panal". En un partido de fútbol, un equipo cae 7 a 0 intimidado por el rival y su barra. Ante una jugada, una niña grita que es penal, pero todos entienden que se refiere a un panal, y la barra del equipo rival huye despavorida, lo que le permite al equipo perdedor remontar.

Se acabó la jodedera en contra de nosotros, los que perdíamos. Los del equipo del centro se sintieron huérfanos y empezaron a flaquear. $\mathrm{Y}$ comenzamos a socar la tuba $\mathrm{y}$ pun, pun, pun, empujamos los siete goles que nos llevaban de ventaja y metimos uno de feria.

Nunca, en la historia del fútbol del mundo, ningún equipo ha tenido una victoria más aplastante. ¡Palabra!

En la publicidad que distribuía promocionando su taller literario, la escritora peruana radicada en Costa Rica, Gladys Russell Huicí, escribía: "La más bella anécdota pierde efecto si no se la sabe contar bien". Ésa es la clave de este libro: convertir anécdotas de la vida real en textos con carácter y oficio literarios. 
En la propia dedicatoria del libro, Zúñiga revela que la fuente de este libro es su hermana, Adela María, pues ella le contó las historias que él recoge en el volumen. Pocos autores revelan las verdaderas fuentes de su trabajo, pues a muchos les encanta ser el único nombre vinculado a sus creaciones. Otra muestra más de la humildad de Zúñiga.

Alfonso Chase, poeta e investigador, comenta sobre la obra:

De este libro emerge Francisco Zúñiga Díaz como uno de nuestros mejores narradores, superándose en su oficio constantemente, y dándole a su trabajo literario esa dignidad y esa claridad tan difícil de encontrar en nuestra literatura contemporánea.

Todos los domingos (1983) es la vuelta de Zúñiga a la periferia urbana, específicamente a la barriada, a la pulpería. De nuevo, la ironía se cuela entre las páginas de sus cuentos. La imagen lezamiana de "Aquí voy yo, Andrés", una vez más, es convocada tras el retorno a la jungla, reemplazando al desenlace jocoso y sorpresivo.

Así se percibe en el cuento "El crimen de anoche:"

Se dirigió a la empresa a retirar el periódico de la mañana y comenzó a vocear, con voz apagada, tenue, casi sin voz: "Con el crimen de anoche, las últimas noticias".

El sol, paso a paso, en un desgano de cansancio, fue colocándose en la mitad del cielo.
La contraportada del volumen comenta lo siguiente:

Ajenos a cualquier especulación formal y artificiosa, recrea los pequeños y cotidianos momentos del hombre de una manera clara, fluida, lectura agradable que nos hermana con las mil y una peripecias del ciudadano de la calle.

Yo no tengo ningún muerto (1986) es un libro especial dentro de la obra de Zúñiga. Volumen dedicado a su esposa y a su hijo, el libro fue publicado gracias al esfuerzo de Grupo Jade, y contó con la portada e ilustraciones de Héctor Marín, Eduardo Arguedas, Jorge Sánchez, Frans Wuytack y Hugo Díaz.

Estética y temáticamente, el volumen marca una continuidad con Los dos minutos y otros cuentos (1976). Además del desolador elemento urbano, Zúñiga retoma su gusto por el tema social, ligado a las luchas populares, revolucionarias, la injusticia que sufre el pobre, aplastado por la maquinaria del poder. La imposibilidad de hacerle frente al sistema se vuelve una carga que, al final, se termina soportando para sobrevivir.

En ese sentido, uno de sus cuentos más amargos es "La decisión", donde el tema del honor se plantea ya no con la sutil ironía de Sir John Falstaff, sino con desesperanza absoluta, como en Ratones y Hombres:

Y aquí me ve usted, estimado compatriota que tuvo la osadía de venirse como exiliado ahora, doce años después, anclado en este parque. No 
tengo trabajo y el último lo perdí. Soy ahora un harapo, un guiñapo, un pordiosero inmundo, un gusano de mierda que se pudre en la gusanera.

Le voy a contar una historia nada más. Debería callarla por honor, pero, ¿qué demonios es el honor?, ¿qué cosa es eso que se llama dignidad?

El personaje sucumbe ante la fuerza de las desgracias y la mala suerte que no dejan de perseguirlo, tras el abandono de la patria.

Tuve deseos, palabra, de pegarme un tiro. De aventurarme en una de las intentonas contrarrevolucionarias para morir en acción. Pero soy cobarde y no hice ni lo uno ni lo otro. No pagué la renta, atrasada en el cuarto que alquilaba. Me emborraché. Gasté los quinientos pesos en licor y perdí el puesto.

Dormí una semana en un parque. Soporté hambre por ocho días. Estaba mugroso, abochornado, derrotado, sin ninguna esperanza.

Pasó el homosexual de los quinientos pesos y me fui con él.

Ese ambiente de tristeza y desolación queda retratado de manera más desnuda y descarnada en el último cuento del volumen, el cual, precisamente, le da su título al libro, Yo no tengo ningún muerto:

Puede que de verdad estén muertos y yo no busco muertos. No tengo ningún muerto, no se me ha muerto nadie, ni voy a tener muertos nunca en la vida.
Absuélvame, padre, o condéneme. Puede ser que yo no tenga ni corazón. Me dijo una vecina que también los habían matado cuando yo quedé sin sentido por la violación, pero yo no lo creo.

Terminemos, padre, pero ya. ¿No ve que debo irme rápido para seguir buscándolos?

Uno de los juicios más contundentes sobre el libro lo ofrece, una vez más, Alberto Cañas:

Por ahí se ha reprochado a Zúñiga Díaz que es siempre el mismo. Hay gente que espera de los creadores que cambien de un lado a otro, que escriban hoy de una manera diferente a como ayer lo hicieron. Total, que de alguna manera se procura que el escritor no desarrolle una manera propia... Pero Francisco Zúñiga sigue siendo el mismo, y no encuentra, supongo, razón para cambiar. Si la manera de contar que ha encontrado le sirve, si dentro de ella se maneja con soltura, ¿por qué le vamos a pedir que cambie?

Cuentos de patria y muerte (1995) es uno de los tres libros que publica en 1995. Este curioso suceso se presenta debido a su temor de morir y no verlos publicados, evidencia de una carrera contra el tiempo en la que su salud no le permitiría el tiempo suficiente para revisar ni corregir.

Sus tendencias socialistas no habían hallado mucho eco en sus propios textos durante toda su carrera. La crítica social que encontramos en textos anteriores se 
justifica a partir de ese realismo rural al cual, ya lo hemos comentado, Zúñiga era tan afecto, y que a veces solía dejarlo de lado por la brutalidad del realismo urbano. Inclusive, en Yo no tengo ningún muerto (1986), el tema revolucionario es abordado de manera panorámica.

Resulta muy interesante y revelador que un autor que siempre abogó por que las tendencias ideológicas no debían sobrepasar la trama, ni los demás recursos literarios de los que dispone un autor, se permita esa libertad en sus últimos trabajos. Talvez, la respuesta pueda encontrarse en una situación terrible.

Su salud empeora a cada instante. El enfisema carcome sus pulmones, y la quimioterapia lo único que hace es deteriorar su ya quebrantada salud. Zúñiga es un autor lúcido, y con esa lucidez que caracteriza su prosa, sabe que estos serán los últimos cuentos que verán la luz. ¿Sentirá Zúñiga que la muerte lo libera, que tiene carta blanca y que no le debe nada a nadie?

A su manera, estos cuentos son la despedida de aquellos ideales revolucionarios y socialistas de juventud, en los que creyó firmemente, para luego asumirlos como fracasos. Zúñiga no tuvo que ver llegar la Perestroika y la caída del muro de Berlín para saber que el comunismo no iba para ningún lado.

Son cuentos sin esperanza, rasgo que vemos por primera vez en su literatura. La muerte oficial, la ofrecida por las armas del gobierno, se pasea por sus páginas, acabando con las vidas y, de paso, con los sueños de los revolucionarios. Lo sorprendente de este volumen es que, contrario a lo que persiguió durante toda su trayectoria, se trata de cuentos que carecen de un desenlace sorpresivo. Los protagonistas mueren, o algo peor. Desde la primera línea, se intuye que ya no existen posibilidades para ellos. El ejercicio narrativo se vuelve como el juego del gato y el ratón y el lector lo intuye.

El autor le da más importancia a la imagen, al aroma, al sonido de la muerte, del fracaso, de la opresión. Resulta llamativo el uso de este último término, opresión, justificado por la temática. Curioso, porque es un término que no suele utilizar Zúñiga en su vocabulario, al menos en sus libros previos. Inclusive, su novela, publicada el mismo año, parece ofrecer alguna salida a los personajes, pero estos cuentos no lo hacen. El autor que siempre nos ofrece una esperanza, por pequeña que sea, ha renunciado a ella.

Así se nos presenta el narrador en el final de su cuento "El desempate:"

Era una anciana acabada, que husmeaba y husmeaba con un fusil inutilizado, entre los escombros, completamente loca.

¿Por qué el fusil? ¿Por qué Juvenal jugaba la pelota? El fusil estaba inservible y la viejecita lo tenía listo para su propia venganza

Juvenal contemplaba las acciones de la abuela, pateando y pateando, a modo de bola, la cabeza desprendida de algún tronco muerto, vaya yo a saber si de soldado o guerrillero. 
Son los últimos cuentos de Zúñiga, su testamento literario, la derrota de sus ideales de juventud, la renuncia a sus propias convicciones. Como en sus otros libros, el título es una imagen lezamiana en sí mismo: nombra y oculta. Son cuentos de patria por la lucha, la contraposición a la tiranía, pero esa patria ya está muerta, no hay nada que pueda hacerse. Tal vez, de haber tenido tiempo, los habría corregido.

Afortunadamente para su legado, algunos cuentos escritos con anterioridad se publicaron al año siguiente, convertidos en su último libro publicado.

La encerrona de la Chupeta y otros desbarajustes (1996) es, como edición, el mejor de sus libros. Como luciera en el libro Sonetos de amor en bicicleta (1977), Zúñiga vuelve a formar tándem con uno de los dibujantes más importantes de la caricatura costarricense en el siglo XX, Hugo Díaz. La edición, cuidadosamente realizada por la EUNED, se convierte en un volumen de lujo. La pluma de Díaz ilustra cada uno de los cuentos.

La editorial, y el hecho de constituirse en el volumen veintisiete de la colección Vieja y nueva narrativa costarricense, le dan, en su última publicación, el homenaje que muchos han creído que se merecía desde hacía tanto tiempo. Terminados en 1994, los cuentos pasaron por todo un año de trámites en la EUNED, hasta su publicación en marzo de 1996. Podemos afirmar, con la certeza que da la cercanía y la convivencia, que Zúñiga tenía miedo de que su salud no le permitiese ver el libro editado.

Lo último que Zúñiga escribió de este volumen fueron las dedicatorias. Todas ellas van dirigidas a personas del Taller del INS. La propia dedicatoria inicial del volumen también va dirigida a los integrantes de este colectivo, aunque de manera general y abierta, sugerente para todos los que ya se habían ido, pero que habían formado parte de él:

A mis compañeros del taller literario del Café Cultural Francisco Zúñiga Díaz,

Fraternalmente, El autor.

El cuento "¡Tango que me hiciste mal...!" está dedicado a Claudio Antonio Cardona Cooper, Toño Cardona, con quien sostuvo una polémica rimada, al mejor estilo de Góngora y Quevedo. Aunque, en honor a la verdad, sería más justo decir que siguieron el modelo de la que sostuvieron Eduardo Calsamiglia y Aquileo Echeverría, dada su entrañable amistad.

Tanto Cardona como Zúñiga eran hombres de verso fácil y narrativa picaresca. El desenlace no solo hace honor al manejo que hace Zúñiga de la sorpresa, sino que evidencia la misma chispa que, en muchos poemas y narraciones, mostró Cardona al compartirlos en el Taller del INS. La conclusión, en sí misma, habla más que la propia dedicatoria del autor:

Que dice mi mamá (surgió la voz del chiquillo) que le mande la plata de la pensión y que me compre unos zapatos y unos pantalones...

La nostalgia de Gardel le hizo sus arrumacos y escribió su recado de respuesta: 
Mano a mano hemos quedado: los favores recibidos creo habértelos pagado y si alguna deuda chica, sin querer se me ha olvidado, en la cuenta del otario que tenés... me la cargás.

El cuento "Mardo, la intentona y yo" está dedicado a la poeta afrocaribeña Delia Mc Donald. La dedicatoria del cuento se justifica a partir de una experiencia que la poeta tuvo con un policía prepotente. Mc Donald contó la anécdota en una sesión del taller en 1994, y Zúñiga ya tenía preparado, para su siguiente volumen, un cuento sobre la estupidez de algunos miembros de las fuerzas del orden. Nada más fácil que dedicarle aquellas páginas. Hay que decir que la poeta quedó más que complacida por la dedicatoria.

El cuento "La carreta sin bueyes" está dedicado al cuentista William Flores, de quien. Zúñiga siempre se mostró muy orgulloso. Colega de Zúñiga en los avatares narrativos, Flores ganó en 1989 la rama Joven Creación del concurso de la Editorial Costa Rica, con su libro de cuentos Dinosaurios en la noche.

El cuento principal, el último del libro y el último texto publicado en vida por Zúñiga Díaz, La encerrona de la Chupeta, está dedicado a Henry López. Según el propio López, él fue la persona con la cual Zúñiga empezó el Taller del INS. Se reunían ambos a la hora del almuerzo y en el receso de café a las tres de la tarde, y allí compartían los textos que escribían. En más de una ocasión, los testigos silenciosos de esas reuniones eran las manchas de café que quedaban en las hojas. Un curioso caso de aquella teoría de hombres como
Vico y Nietzsche, que apostaban sus vidas al albur de que la historia es cíclica.

Con López, inicia Zúñiga la historia del Taller y con López se cierra. Si la historia es cierta, es un curioso final. Una vez más, el narrador, el artista, se impone, y nos envuelve en su propia ficción, a nosotros que solo deberíamos asistir como simples espectadores, pero mediante sus dedicatorias, nos convierte en personajes de una historia de la que no sabemos nada. Como hacen los autores con sus personajes.

\section{La musa de fuego}

"O for a Muse of fire, that would ascend The brightest heaven of invention". William Shakespeare. Henry $V$

Las formas básicas de literatura, las cuales fueron establecidas desde la antigüedad clásica, apuntan a tres configuraciones: épica, lírica y drama. Cada una de ellas, con el transcurrir de las épocas, ha mostrado variantes en muchos ámbitos. Entre ellas, su longitud, para empezar. A la épica se contrapone la fábula, en el caso de la narrativa; la oda al aforismo o epigrama, etc.

En el caso de la lírica, una de las formas breves que más éxito ha tenido, a pesar de sus dificultades técnicas ha sido el soneto. Cada estructura literaria tiene sus lineamientos, sus aspectos que todo autor debe cubrir para culminarla con éxito. El soneto es el equivalente poético del cuento. Debe contar una historia o presentar una escena en un espacio breve, desatar los nudos y no dejar cabos sueltos. Su limitante pareciera ser la estructura: catorce versos, divididos en dos cuartetos y dos tercetos, en su versión italiana, o tres cuartetos y un 
dístico en su versión inglesa. Esa capacidad de concretar, la cual es ideal en el autor que aborda un soneto, ya fue descrita por Shakespeare en el prólogo al primer acto de su drama histórico Henry $V$ :

Turning the accomplishment of many years

Into an hour-glass...

Debido a su estructura, suele asumirse que el soneto es una forma rígida, que no ofrece variantes. Sin embargo, no existen dos sonetos iguales, algo que no puede decirse de otras formas literarias. La presión que experimenta el autor por cumplir todas sus exigencias formales le permite encontrar tierra fértil para su imaginación. La riqueza temática y metafórica que suele deparar el soneto parece hacer surgir esa musa de fuego a la que se refiere Shakespeare en el prólogo ya citado.

Quizá se deba a su experiencia previa como narrador y cuentista, pero cuando Zúñiga Díaz se enfrenta al soneto, ya tiene terreno ganado. Desatar nudos y cerrar cabos sueltos es una de sus especialidades. Ha publicado cuatro libros de cuentos $(1965,1967,1976$ y 1978) antes de que publique su primer libro de poesía, en 1980. Un libro que, curiosamente, está conformado por sonetos.

Ya desde su título, Geografía sencilla (1980), comprendemos que la estética del poemario apunta a ese realismo periférico que caracteriza las narraciones de los libros iniciales de Zúñiga. Sin embargo, en otros autores, ese realismo se queda en la descripción, en la caricia superficial de las emociones. Pero recordemos que la imagen lezamiana de Zúñiga roza la introspección, el pesimismo filosófico del que observa y contempla. Es la soledad que respiran los héroes de Adolfo Herrera García y José Marín Cañas en el soneto "No sé:"

Pensar en no pensar. ¿Lo hago, no lo hago?

Y eso de adentro se me vuelve vago

Y deja el corazón desvanecido.

Es en ese absurdo trágico de la naturaleza y sus elementos donde Zúñiga Díaz se siente a sus anchas, y el autor nos permite entrar en contacto con su musa de fuego. Véase el soneto Acuarela:

Los techos no se ven, son de la noche

Cuando la tierra esparce su derroche

Y el viento taciturno la desvela.

A menudo, esa insatisfacción vital se relaciona con el entorno, como una extrapolación del conflicto interno. Aunque a veces, la desazón se revela desde el propio proceso reflexivo, como ocurre en el soneto "Ese recuerdo necio:"

Se me anida en el labio la aveniencia

De tu beso fugaz, con la florada

De un colibrí de luz, de flor fugada

Y un rastro de tu aroma, tenue esencia.

Pero no todo es desolación en el acto contemplativo de Zúñiga. En el imaginario 
colectivo de la literatura costarricense, la desolación apocalíptica le corresponde al escritor originario de la meseta central. El autor nacido fuera del área metropolitana, a pesar del aire derrotista, encuentra el escape justo en el paisaje y en la voz de la naturaleza. En los sonetos de Zúñiga, la esperanza se mantiene oculta hasta el último minuto, como en el soneto "Anochecida:"

La noche, mientras tanto, se ilumina

Y la brisa es esencia que combina

Un paisaje de aroma, arena y mar.

Sobre el libro, apunta Alfredo Cardona Peña, poeta radicado en México, este testimonio recogido en los datos curriculares sobre Francisco Zúñiga, documento preparado para presentar la candidatura del autor para el Premio Magón en 1994:

Como su nombre lo indica, se trata de una geografía poética sencilla, como es la gente de nuestros campos, más cerca de la paz que de las cosas complicadas. Son poemitas como acuarelas de paisaje. Abundantes como estamos de temas oscuros y difíciles, nos llegan sonrientes con sus almas puras.

\section{Bibliografía}

Aguilar Vargas, M. (1994). Pequeñas huellas. San José: Biblioteca del Café.

Brenes, Joan B. (1996). Pre-monición. San José: Biblioteca del Café.

Castro, H. (1996). Basiliscos y Rufianes. San José: Biblioteca del Café. (2011). Una noche en Zoologischer Garten. San José: Editorial Ipeca.

Láscaris, C. y Malavassi, G. (1975). La carreta costarricense. San José: Ministerio de Cultura, Juventud y Deportes

Lobo Bejarano, L. G y Quesada Soto, Á. (2006). Eduardo Calsamiglia: Obra Literaria. Sana José: Editorial de la Universidad de Costa Rica.

Marcelo, C. (1994). Todo es lo mismo y no es lo mismo. San José: Biblioteca del Café.

McDonald, D. (1994). El séptimo círculo del obelisco. San José: Biblioteca del Café.

Mena Moya, R. A. (2005). Poesía Humorística: Antología del Humor Poético de Costa Rica, España e Hispanoamérica. San José: Librería Francesa.

Picado, M. (1978). Testimonio de entonces. San José: Editorial Costa Rica.

Piedra, M. (1991). Amanda Mar. San José: Biblioteca del Café.

Varios (1995). Francisco Zúñiga Díaz: Datos Curriculares. S/R.

Varios. (1968). Anuario del cuento costaricense. San José: Editorial Costa Rica.

Varios (1979). ¿Quién detiene la aurora? San José: UPINS.

Varios (1982). Juego de cuentos. San José: Ediciones del Café Cultural. 
Varios (1983). Convivio, colección de poesía. San José: Ediciones del Café.

Varios (1994). Cuento y poesía. Ganadores de la revista Cultura. San José: Editorial de la Universidad Estatal a Distancia.

Varios (1997). Luna entre milpas. San José: Ediciones del Café Cultural.

Vargas, J. A, V, M. y V, C. (1990). Antología poética ramonense. San José: Ediciones Zúñiga y Cabal.

Villalobos, C. (1992). Los trayectos y la sangre. San José: Ediciones Zúñiga y Cabal.

Zúñiga Díaz, F. (1965). Trillos y nubes. San José: Editorial Tormo.

(1967). La mala cosecha. Santiago: Imprenta Horizonte.

(1976). Los dos minutos y otros cuentos. San José: Editorial Costa Rica.

(1977). Sonetos de amor en bicicleta. San José: Ediciones Dromedario.

(1978). El viento viejo. San José: Editorial Costa Rica.

(1978).Técnicas de redacción. San José: Instituto de Capacitación de Seguros.
(1979). El soneto en la literatura costarricense. San José: Editorial de la Universidad de Costa Rica. (1980). Geografía Sencilla. San José; Editorial Costa Rica. (1983). Todos los domingos. San José: Editorial Costa Rica. (1983). El ABC de los seguros. Con Carlos Alberto Aguilar Montoya y Gerardo Leal. San José: Ediciones del Café Cultural. (1986). Yo no tengo ningún muerto. San José: Ediciones Presbere, S.A. (1991). Carlos Luis Sáenz: el escritor, el educador y el revolucionario. San José: Ediciones Zúñiga y Cabal. (1995). Cuentos Prohibidos. San José: Biblioteca del Café. (1995). El amor y algunos entredichos. San José: Ediciones Zúñiga y Cabal.

(1995). Cuentos de Patria o Muerte. San José: Ediciones Zúñiga y Cabal.

(1995) ...Y hubo un pueblo de niños. San José: Ediciones Zúñiga y Cabal. (1996). La encerrona de la chupeta y otros desbarajustes. San José: Editorial de la Universidad Estatal a Distancia. 